\title{
EVALUATION OF VITAMIN K (MENAQUINONE-7) STABILITY AND SECRETION IN GLUCOSE AND GLYCEROL-BASED MEDIA BY BACILLUS SUBTILIS NATTO
}

\author{
E. MAHDinia ${ }^{\mathrm{a}}$, A. Demirci ${ }^{\mathrm{a} *}$, and A. BerenJian ${ }^{\mathrm{b}}$ \\ ${ }^{\mathrm{a}}$ Department of Agricultural and Biological Engineering, The Pennsylvania State University, University Park, PA, \\ 16802. USA \\ ${ }^{\mathrm{b}}$ Faculty of Science and Engineering, The University of Waikato, Hamilton, 3240. New Zealand
}

(Received: 22 August 2018; accepted: 29 April 2019)

\begin{abstract}
Menaquinone-7 (MK-7) is a type of vitamin K. MK-7 is produced via bacterial fermentation, and in order to reach the desired product purity, several downstream processing steps, including extraction, drying, ultrasonication, must be carried out. These processes, however, need to be carried out in such fashion to ensure the least amount of vitamin $\mathrm{K}$ lost and maximum recovery into the end-product. Therefore, in this study, drying, storage at 4 and $-20{ }^{\circ} \mathrm{C}$, and ultrasonication steps were evaluated under different conditions. Static liquid fermentations were conducted in McCartney bottles to explore the maximum MK-7 secretion potentials in different glycerol and glucose-based media compositions that were optimized in our previous studies. Maximum $32.5 \pm 0.4 \mathrm{mg} \mathrm{l}^{-1}$ and $14.6 \pm 0.4 \mathrm{mg} \mathrm{l}^{-1}$ concentrations were achieved in glycerol and glucose-based media, respectively. Concentrations of MK-7 produced under same fermentation conditions in $30 \mathrm{ml} \mathrm{McCartney} \mathrm{amber} \mathrm{bottles} \mathrm{with} 3 \mathrm{ml}$ of media in them and in $75 \mathrm{ml}$ culture tubes with $20 \mathrm{ml}$ media were compared. Also, ultrasonication, drying, and storage conditions were investigated to ensure the least amount of vitamin $\mathrm{K}$ is lost. Results showed that drying under forced air flow was the fastest, thus, demonstrated a better preservation of the vitamin, and should replace vacuum drying. Ultrasonication for $15 \mathrm{~min}$ seems to be safe and sufficient for phase transition for analysis. Also, storage at refrigerated temperatures seems to preserve MK-7 at least for one week. Furthermore, fermentations in McCartney bottles indicated how MK-7 concentrations are distributed in different zones of the static liquid broth. Culture tube results provided the conclusion as of how the metabolism of MK-7 changes in static fermentation when the scale-up process begins from McCartney bottle to culture tubes. Results in general showed a clearer road map to ensuring better quality and preservation of the valuable end-product, and illuminated more the path to further scaling up of the fermentation process for commercial production of MK-7.
\end{abstract}

Keywords: MK-7, vitamin K, stability, Bacillus subtilis, solid state fermentation, liquid state fermentation

Vitamin $\mathrm{K}$ comes in two major forms. One of those forms is phylloquinone, which has a singular structure, which is majorly the plant form of vitamin K. The other form, known as menaquinones, has several subtypes (MK-1 to MK-15). Menaquinones are vitamin $\mathrm{K}$ forms found in foods of animal origin, and also are biosynthesized by several microbial strains (MAHDINiA et al., 2017a). As a result, the most practical way to produce vitamin $\mathrm{K}$ on an industrial scale is through microbial fermentations (BERENJIAN et al., 2015). MK-7 is the subtype of vitamin $\mathrm{K}$ that stands out as the most potent form for production on an industrial scale (SCHURGERs et al., 2007).

Bacillus subtilis natto strains in both Solid State Fermentation (SSF) and Liquid State Fermentation (LSF) strategies have been investigated for potential MK-7 production on an industrial scale (BERENJIAN et al., 2011a; SINGH et al., 2015). In this regard, fermentation in

\footnotetext{
* To whom correspondence should be addressed.

Phone: +1 (814) 863 1098; fax: +1 (814) 863 1031; e-mail: demirci@psu.edu
} 
McCartney bottles and shake-flasks have been investigated in numerous past studies (SATO et al., 2001; BERENJIAN et al., 2014; MAHDINIA et al., 2017b). Also, in our previous studies, the feasibility and conditions for scaling up MK-7 fermentation from bottles to bench-top biofilm reactors were investigated. Results indicated that biofilm reactors were superior to suspendedcell bioreactors in MK-7 biosynthesis (MAHDINIA et al., 2017b, 2018a, 2018b, 2019a). However, the integrity and stability of MK-7 as it is produced in the fermentation process need to be studied for efficient analysis or downstream processes. Therefore, this study focused on MK-7 stability through the processes and also on its biosynthesis in bottles and tubes with different glucose and glycerol-based media compositions that were optimized earlier in bioreactors.

\section{Materials and methods}

\subsection{Microorganisms and media}

Bacillus subtilis natto (NF1) was isolated from commercial natto (Mizkan Co., Ltd., Handa, Japan), as previously described (MAHDINIA et al., 2017b). For culturing, Tryptic Soy Broth (TSB) medium (Difco, Detroit, MI) fortified with 5\% (w/v) glucose (Tate \& Lyle, Decatur, IL), and $0.8 \%$ yeast extract (Biospringer, Milwaukee, WI) was used (MAHDINIA et al., 2018a). To TSB medium consisting of glucose (Tate \& Lyle), $17.5 \mathrm{~g} \mathrm{l}^{-1}$ tryptone (Marcor, Carlstadt, $\mathrm{NJ}$ ), $3 \mathrm{~g} \mathrm{l}^{-1}$ of soytone (Marcor), $5 \mathrm{~g} \mathrm{l}^{-1}$ of $\mathrm{NaCl}$ (EMD Chemicals, Gibbstown, NJ), and $2.5 \mathrm{~g} \mathrm{l}^{-1}$ of $\mathrm{K}_{2} \mathrm{HPO}_{4}(\mathrm{VWR}$, West Chester, PA), different percentages of glucose $(\mathrm{w} / \mathrm{v})(0,5$, 10 , or $15 \%$ ) and $8 \mathrm{~g} \mathrm{l}^{-1}$ of yeast extract (Biospringer) were added to fortify (designated as TSB 5\%, TSB 10\%, etc.). Also, two compositions of the glycerol-based medium were evaluated. The lesser concentration glycerol-based medium (LGM) contained $45 \mathrm{~g} \mathrm{l}^{-1}$ glycerol (EMD), $10 \mathrm{~g} \mathrm{l}^{-1}$ soytone (Marcor), $5 \mathrm{~g} \mathrm{l}^{-1}$ yeast extract (Biospringer), and $0.6 \mathrm{~g} \mathrm{l}^{-1} \mathrm{~K}_{2} \mathrm{HPO}_{4}$ (VWR) (MAHDINIA et al., 2018b). The higher concentration glycerol-based medium (HGM) consisted of $50 \mathrm{~g} \mathrm{l}^{-1}$ glycerol (EMD Chemicals, Gibbstown, NJ), $189 \mathrm{~g} \mathrm{l}^{-1}$ soytone (Marcor), $50 \mathrm{~g} \mathrm{l}^{-1}$ yeast extract (Biospringer), and $0.6 \mathrm{~g} \mathrm{l}^{-1} \mathrm{~K}_{2} \mathrm{HPO}_{4}$ (VWR) (MAHDINIA et al., 2018a).

\subsection{Fermentation}

1.2.1. Inoculum preparation. Inoculum was prepared in TSB medium as described in our previous studies (MAHDINIA et al., 2017b).

1.2.2. Fermentation in McCartney bottles. Amber McCartney bottles $(30 \mathrm{ml})$ were used containing $3 \mathrm{ml}$ of each medium. Bottles were incubated statically at $37^{\circ} \mathrm{C}$ for $96 \mathrm{~h}$. Then the entire content in the bottles was analysed for MK-7 concentration.

1.2.3. Fermentation in culture tubes. For tube fermentations, $75 \mathrm{ml}$ culture tubes contained $20 \mathrm{ml}$ of each medium composition. Tubes were also incubated at $37^{\circ} \mathrm{C}$ statically for $96 \mathrm{~h}$. Then, $3 \mathrm{ml}$ samples were drawn from the top layer, the middle of the broth separately ( $3 \mathrm{ml}$ from each position) and from the bottom of the tubes and were analysed for MK-7. 


\subsection{Stability evaluations}

1.3.1. Drying. Pure MK-7 was procured with $99.9 \%$ purity for positive controls and standard curves (Chroma Dex Corporation, Irvine, CA). MK-7 standard solutions $\left(10 \mathrm{mg} \mathrm{l}^{-1}\right)$ in methanol were prepared from pure MK-7. First, without any drying step, one set of samples were analysed to confirm the original concentration. Others were dried under forced air or nitrogen flow $\left(\sim 51 \mathrm{~min}^{-1}\right)$ for a few hours at ambient temperature, vacuum $(<3$ psia $)$ at $37{ }^{\circ} \mathrm{C}$ overnight, then under a fume hood without any forced gas flow or vacuum for up to $72 \mathrm{~h}$ until all pellets were completely dried at ambient temperature. Then, organic mixture $n$-hexane:2-propanol (2:1, v/v) (EMD) with 1:4 (liquid:organic, v/v) ratio was added to the dried pellets and dried again. Under forced gas flows, it took a few hours for the samples to dry with a marginal gas exiting the nozzle to ensure no pellet disturbance or fluidization $(<10$ psig), in vacuum they were dried overnight (BERENJIAN et al., 2011b), and in the fume hood for $72 \mathrm{~h}$ to dry completely. Then, dry pellets were re-suspended in methanol and analysed for MK-7.

1.3.2. Storage. Standard $10 \mathrm{mg} \mathrm{l^{-1 }}$ MK-7 solutions were prepared from pure MK-7 added in typical fermentation medium. Half of the solution was extracted and then dried, and the other half was further split into two halves, and one half was stored at 4 and the other half at $-20{ }^{\circ} \mathrm{C}$. After 7 days, MK-7 concentrations were measured, and the results were compared to samples that were extracted and analysed fresh.

1.3.3. Ultrasonication. MK-7 solutions were prepared in the extracting organic mixture $n$-hexane:2-propanol (2:1, v/v) (EMD) with ratio 1:4 liquid:organic, v/v with $10 \mathrm{mg} \mathrm{l}^{-1} \mathrm{MK}-7$ content. Then, the solution was dried under forced air flow. After that, methanol was added to the pellets, then different periods of ultrasonication $(5,10,15$, and $30 \mathrm{~min}$ at $40 \mathrm{kHz}$ frequency and $500 \mathrm{~W}$ ) were applied to the samples prior to HPLC analysis for MK-7 concentration.

\subsection{Analysis}

1.4.1. MK-7 analysis. MK-7 concentrations in the samples were analysed using HPLC as described in our previous studies (BERENJIAN et al., 2011b; MAHDINIA et al., 2017b).

1.4.2. Statistical analysis. All measurements were repeated at least three times. Average values were obtained and demonstrated with standard errors of the repetitions as error bars.

\section{Results and discussion}

The first research goal was to study the impact of drying and ultrasonication steps, necessary prior to HPLC analysis, on MK-7, and to determine the best parameters to minimize potential losses of MK-7 within the storage time under refrigerated or frozen conditions. The second goal was to find out how MK-7 secretion is taking place at static fermentations at different media compositions that have been implemented in biofilm reactors. 


\subsection{MK-7 stability}

2.1.1. Drying. Once MK-7 is secreted into the broth and the broth is harvested from bioreactors, it needs to be extracted and dried for analysis or purification and freeze-drying for pharmaceutical utilization. In either case, it is important to know how drying may affect MK-7 stability. For analysis, after extraction and separation of the phases, the organic phase is usually dried at ambient temperatures; yet, this can be done under vacuum and with or without forced gas flow onto the evaporating phase.

As shown in Figure 1, drying under forced gas flow would not affect MK-7 significantly and the differences are only about 3 or $4 \%$. However, vacuum drying leads to about $10 \%$ loss, and drying in fume hoods leads to about $30 \%$ drop in MK-7 concentration. Compared to the uncertainty of these measurements, which were less than $1 \%$ throughout the samples, vacuum and fume hood losses are quite significant. This is possibly due to the fact that with forced air or nitrogen the MK-7 is exposed to ambient conditions and light for only a few short hours and therefore remains preserved. The fact that samples dried with air are not significantly different in MK-7 contents from those dried with nitrogen indicates that exposure to ambient oxygen for that short period of time does not affect MK-7 integrity. This enabled the use of air, which is more economical compared to nitrogen gas. Since vitamin K is generally sensitive to light, although extraction and evaporation and injection steps are all carried out in amber vials; exposure to ambient conditions must be minimized (OKANO et al., 2008). This is perhaps another benefit of using the forced air flow for drying beside saving processing time; i.e. by using forced air flow instead of vacuum drying or freeze drying, the samples can be dried in a shorter period of time. Therefore, drying with forced air flow has been used for drying the samples.

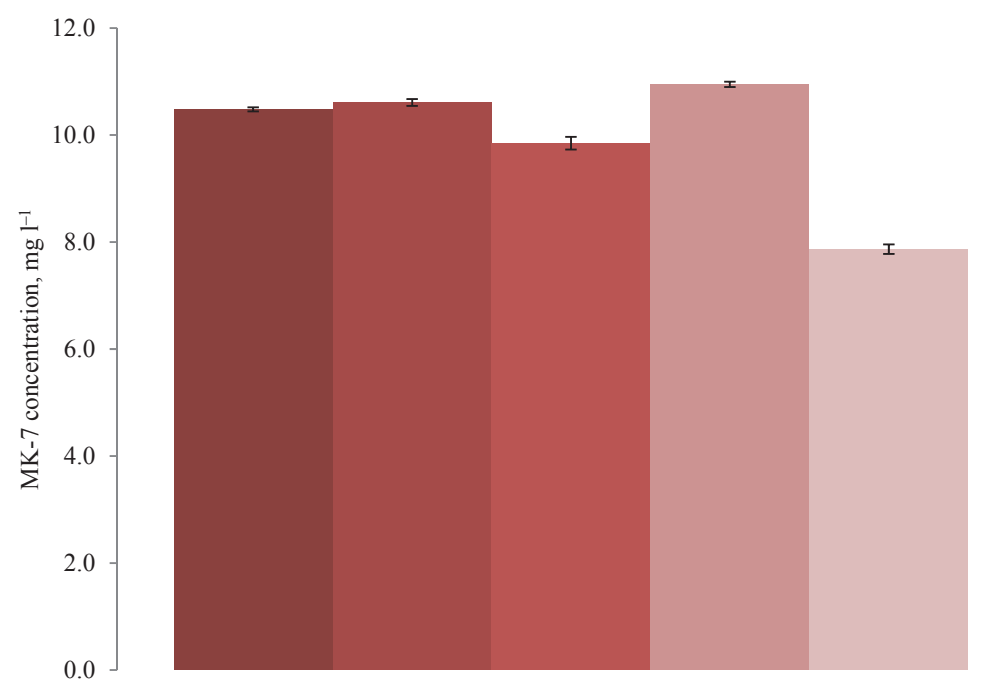

Fig. 1. Effects of different drying methods on MK-7 concentration. The original is the positive control where no drying was applied

ㅁ: Air; $\varpi:$ nitrogen; ㅍ: vacuum; ㄸ: original; $\leftleftarrows:$ no flow 
2.1.2. Storage. Storing the harvested MK-7 for a few days may be inevitable due to the fact that downstream processing steps may not be online as soon as the fermentation cycle is complete. Therefore, it is imperative to ensure that the harvested MK-7 is stored suitably so that losses are minimized. Figure 2 indicates that within 7 days of storage in refrigerator or freezer the MK-7 shows very strong stability and no detectable degradation is observed. The stored samples showed slight deviation with the original solution $(11.1,10.8,11.2$, and 10.4 $\mathrm{mg} \mathrm{l}^{-1}$ as compared to $10.7 \mathrm{mg} \mathrm{l}^{-1}$ in the original solution); which suggest reasonable extraction and HPLC analysis error ranges. These observations reveal that low temperatures preserve chemical structure of MK-7 well and refrigeration is sufficient for that purpose and freezing is not required. This is possibly due to the fact that in storage MK-7 is kept in the dark and away from any light exposure and degradation due to microbial activities is significantly low.

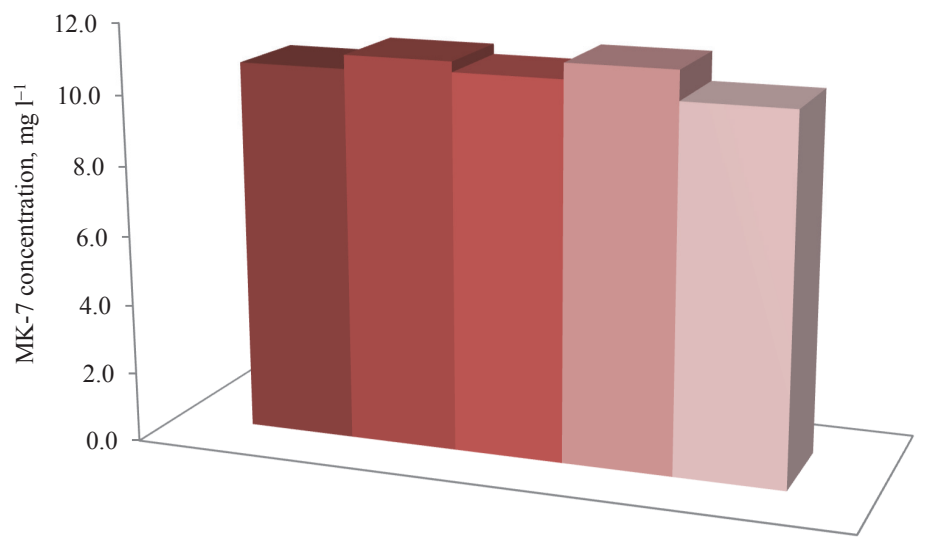

Fig. 2. MK-7 concentration changes in $10 \mathrm{mg} \mathrm{l}^{-1}$ standard solutions stored under different conditions ㅁ: Fresh standard solution; $\square$ : dried standard solution kept at $4{ }^{\circ} \mathrm{C}$ for 7 days; $\square$ : dried standard solution kept at $-20^{\circ} \mathrm{C}$ for 7 days; $\square$ : standard solution kept at $4^{\circ} \mathrm{C}$ for 7 days; $:$ : standard solution kept at $-20^{\circ} \mathrm{C}$ for 7 days

2.1.3. Ultrasonication. Once the harvested MK-7 is dried, the MK-7 pellets need to be re-suspended in pure methanol before HPLC analysis. Although this step is not required for downstream processing of MK-7 in the production plant, it is needed for analytical and quality control purposes in the lab. Since MK-7 has fairly low solubility in methanol and is quite sensitive to high temperatures (SHEARER \& NEWMAN, 2008), one practical way of dissolving the pellets quickly in methanol is to apply ultrasonication at ambient temperatures. Ultrasonication does a very good job in dissolving the pellets; yet, powerful ultrasonication waves may damage the chemical structure of MK-7. In many samples, maximum ultrasonication time is required to ensure that pellets are dissolved. As Figure 3 shows, ultrasonication for $5,10,15$, and $30 \mathrm{~min}$ seems to be safe for MK-7 integrity $(10.0,10.0$, 10.0 , and $10.1 \mathrm{mg} \mathrm{l}^{-1} \mathrm{MK}-7$ concentrations, respectively, as compared to the $10.0 \mathrm{mg} \mathrm{l}^{-1}$ original standard concentration). Therefore, $15 \mathrm{~min}$ of ultrasonication seems to be safe and ample. 


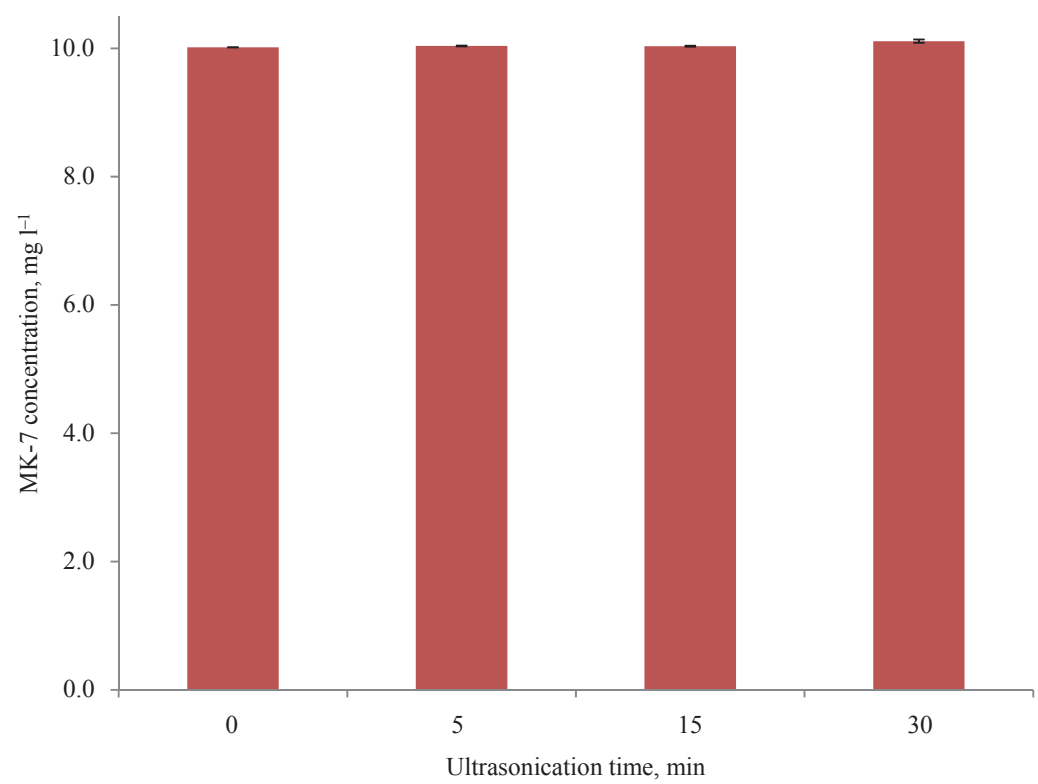

Fig. 3. Effects of different periods of ultrasonication on MK-7 concentration in $10 \mathrm{mg} \mathrm{l}^{-1}$ standard solutions

\subsection{Fermentation in McCartney bottles}

For the second hypothesis in this study, fermentation was carried out in media with different compositions and in different vessels (tubes and bottles). The question was whether MK-7 fermentation, similarly to any fermentation process, is highly dependent on the scale of the fermentation as well as the fermentation strategy (MAHDINIA et al., 2019b). Fermentation in McCartney bottles shows how much potential the $B$. subtilis strain has for MK-7 secretion. Figure 4 indicates that a maximum $32.5 \pm 0.4 \mathrm{mg} \mathrm{l}^{-1} \mathrm{MK}-7$ concentration was achievable by the $B$. subtilis natto in the rich glycerol-based medium. This is basically the highest amount of MK-7 concentration observed in our recent studies in bottles, tubes, or bioreactors. $B$. subtilis is a highly aerobic bacterium, and as biofilm reactor studies indicated, high agitation and higher Oxygen Transfer Rates (OTR) are always favourable for MK-7 secretion (MAHDINIA et al., 2018c, 2018d, 2019c). Thus, it seems that the ample headspace provided in the McCartney bottles above the smaller amount of broth provides enough oxygen diffusion into the fermentation mixture for MK-7 secretion pathways to flourish. Furthermore, pellicle formation by the bacterium enables the dense microbial colonies in the extracellular matrices to float on the surface of the broth, and thus, getting in closer contact with oxygen diffusing from air (MAHDINIA et al., 2018c, 2019c). On the other hand, the very rich glycerol-based medium provides the nutrients required for these robust colonies to expand quickly. This clearly explains why MK-7 is expressed significantly better compared to other medium compositions. Understanding these phenomena is critical in order to tackle any further scaleup steps. The extracellular matrices are beneficial to MK-7 expression, and therefore, biofilm reactors are more efficient in this regard compared to suspended-cell bioreactors (BERENJIAN et al., 2013; MAHDINIA et al., 2018d). However, such rich medium did not seem to have as much efficiency in biofilm reactors; yet, the less rich glycerol medium produced comparable amounts of MK-7 under both regimes $\left(14.7 \pm 1.4 \mathrm{mg} \mathrm{l}^{-1}\right.$ in biofilm reactors compared to 
$18.0 \pm 0.3 \mathrm{mg} \mathrm{l}^{-1}$ in bottles). In the TSB media, fortifying the composition with 5 and $10 \%$ added glucose significantly increased the MK-7 concentrations $(6.0 \pm 0.1,10.7 \pm 0.2$, and $14.6 \pm 0.4 \mathrm{mg} \mathrm{l}^{-1}$, respectively), and all these three compositions showed robust pellicle formation. These concentrations were still lower than those obtained in optimized biofilm reactors with $15 \%$ added glucose (maximum $20.5 \pm 0.5 \mathrm{mg} \mathrm{l}^{-1}$ ). However, with glucose concentrations at $15 \%$ in the bottles, metabolism was inhibited and growth and therefore MK-7 secretion was very poor, so that no pellicle formations were visible at the end of the 96 h. One explanation could be that $15 \%$ glucose inhibited the static fermentation due to higher oxygen demands and low oxygen availability, while in biofilm reactors this was not the case with robust agitation and aeration (MAHDINIA et al., 2018b).

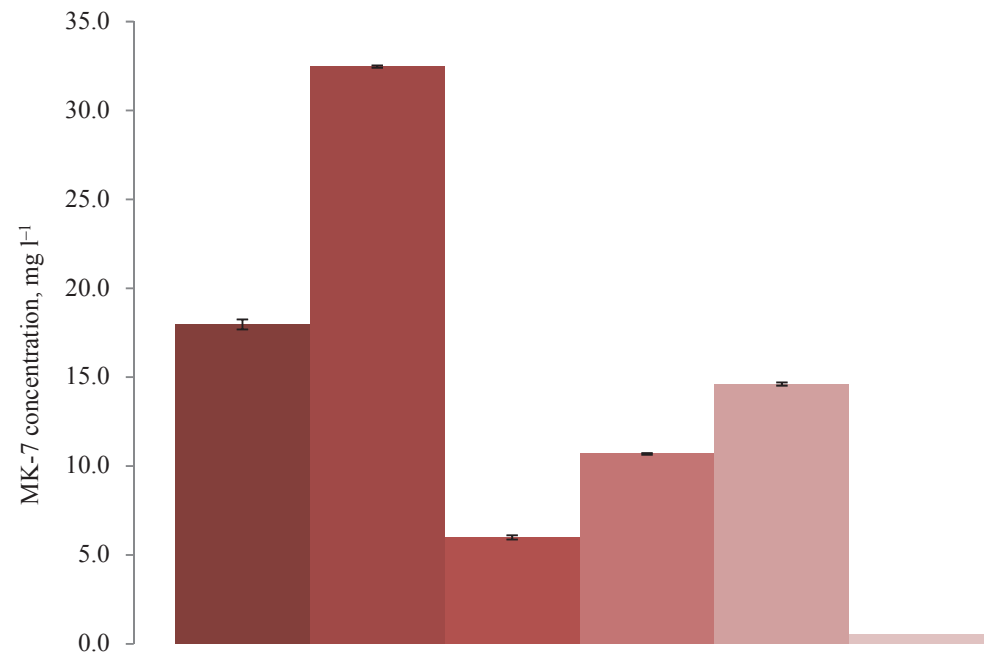

Fig. 4. MK-7 concentration produced in different media and vessels all under static liquid state fermentations

[: $45 \mathrm{~g} \mathrm{l}^{-1}$ glycerol $+10 \mathrm{~g} \mathrm{l}^{-1}$ soytone $+5 \mathrm{~g} \mathrm{l}^{-1}$ yeast extract $+0.6 \mathrm{~g} \mathrm{l}^{-1}$ potassium dihydrogen phosphate;

ㅁ: $50 \mathrm{~g} \mathrm{l}^{-1}$ glycerol $+189 \mathrm{~g} \mathrm{l}^{-1}$ soytone $+50 \mathrm{~g} \mathrm{l}^{-1}$ yeast extract $+0.6 \mathrm{~g} \mathrm{l}^{-1}$ potassium dihydrogen phosphate;

ㅁ: tryptic soy broth $+8 \mathrm{~g} \mathrm{l}^{-1}$ yeast extract; ㅍ: tryptic soy broth $+8 \mathrm{~g} \mathrm{l}^{-1}$ yeast extract $+50 \mathrm{~g} \mathrm{l}^{-1}$ glucose

ㅁ: Tryptic soy broth $+8 \mathrm{~g} \mathrm{l}^{-1}$ yeast extract $+100 \mathrm{~g} \mathrm{l}^{-1}$ glucose;

=: Tryptic soy broth $+8 \mathrm{~g} \mathrm{l}^{-1}$ yeast extract $+150 \mathrm{~g}^{-1}$ glucose

\subsection{Fermentation in culture tubes}

Culture tubes contained $20 \mathrm{ml}$ of broth with relatively less head space. The tubes had a total of $75 \mathrm{ml}$ volume (which is more than twice as much compared to McCartney bottle with 30 $\mathrm{ml}$ of total volume), and therefore, the $20 \mathrm{ml}$ broth had about 3 inches depth in the tubes, while in the McCartney bottles the depth of the $3 \mathrm{ml}$ broth was less than half an inch. As a result, oxygen and nutrient gradient in static mode were significantly worse in tubes. Thus, as expected, the ideal conditions that existed in McCartney bottles in culture tubes no longer exist. The depth of the broth is simply too much for oxygen to diffuse deep and reach the bottoms. However, fermentation in the culture tubes provides enough depth to clearly see the three layers that occur in static fermentation. At the end of the fermentation period and regardless of the media composition, there were three distinct layers formed in the tubes. On the top, there was a thick layer of pellicle formations; in the middle, the broth was clearer and contained mostly planktonic cells; and on the bottom, there were sunken cells. Results show 
that in glycerol-based media, the sunken cells in the bottom zones were significantly richer in MK-7 (Figure 5). One explanation could be that the cells that are dense enough on the surface layers sink to the bottom possibly as they die, and thus release the intracellular MK-7 into the broth, as MK-7 is both extracellularly and intracellularly expressed in B. subtilis (IKEDA \& DoI, 1990). However, in glucose-based media, MK-7 expression is almost negligible when compared to McCartney bottles (barely reaching over $1 \mathrm{mg} \mathrm{l}^{-1}$ ); and as oxygen diffusion is even more critical here, glucose richer compositions are much poorer in MK-7. This may also explain why MK-7 concentrations in the top layers were better than in the middle layers, and also why the richer glycerol-based medium top and middle layers were richer than those layers in the less rich medium; i.e., the rich medium required more oxygen availability, and therefore, in the top layers, did a better job providing higher cell intensity in the floating pellicle formations. Overall, the MK-7 secretion in the tubes were significantly lower than in McCartney bottles (over $32.0 \mathrm{mg} \mathrm{l}^{-1}$ maximum concentrations in bottles, whereas they were barely over $5.0 \mathrm{mg} \mathrm{l}^{-1}$ in tubes). The results in the culture tubes show how MK-7 distribution in different zones in liquid static fermentations occurs, as expected because of different oxygen availability (MAHDINIA et al., 2019d).

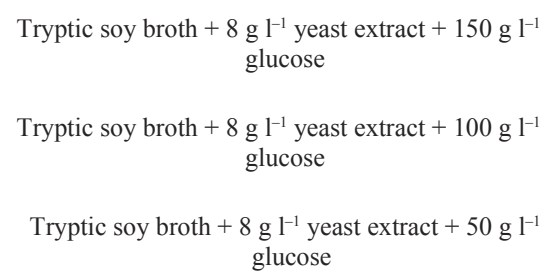

Tryptic soy broth $+8 \mathrm{~g}^{-1}$ yeast extract

$50 \mathrm{~g} \mathrm{l}^{-1}$ glycerol $+189 \mathrm{~g} \mathrm{l}^{-1}$ soytone $+50 \mathrm{~g} \mathrm{l}^{-1}$ yeast extract $+0.6 \mathrm{~g}^{-1}$ potassium dihydrogen phosphate

$45 \mathrm{~g} \mathrm{l}^{-1}$ glycerol $+10 \mathrm{~g} \mathrm{l}^{-1}$ soytone $+5 \mathrm{~g} \mathrm{l}^{-1}$ yeast extract $+0.6 \mathrm{~g}^{-1}$ potassium dihydrogen phosphate
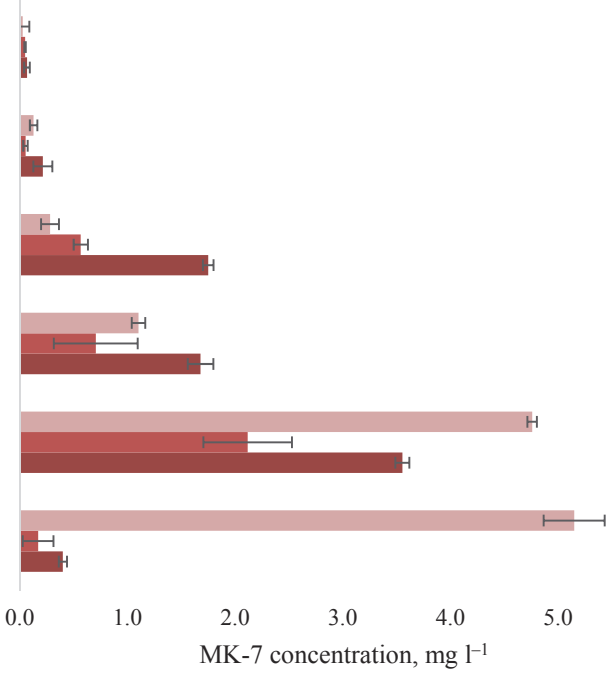

6.0

Fig. 5. MK-7 production in media with different compositions at the top, middle, or bottom zones of the broth in culture tubes

ㅍ: Bottom; ㅍ: middle; 프: top

\section{Conclusions}

MK-7 stability and integrity were investigated under different conditions during the drying, storage, and ultrasonication steps necessary for analysis and perhaps downstream processing. Results indicated that when the MK-7 produced was quickly dried using forced air flow after extraction, over $95 \%$ of it could be preserved. Also, refrigeration at $4{ }^{\circ} \mathrm{C}$ was sufficient to preserve the MK-7 product in the original broth for at least 7 days, should the downstream processing or analysis be delayed. Moreover, ultrasonication for $15 \mathrm{~min}$ seemed to be harmless and sufficient prior to analysis. Besides, fermentations in McCartney bottles and 
culture tubes revealed that the conditions in the McCartney bottles were ideal to explore the maximum potential for MK-7 secretion, which occurred in the glycerol-rich medium (32.5 $\left.\pm 0.4 \mathrm{mg}^{-1}\right)$ seconded by TSB medium fortified with $10 \%$ glucose $\left(14.6 \pm 0.4 \mathrm{mg} \mathrm{l}^{-1}\right)$. Finally, in culture tubes, as expected, the MK-7 concentrations were much lower than in bottles (Maximum 5.1 $\pm 0.2 \mathrm{mg} \mathrm{l}^{-1}$ ); yet they provided good insight as of how MK-7 secretion was distributed in different zones of the static liquid fermentation.

This work was supported by the USDA National Institute of Food and Agriculture Federal Appropriations under Project PEN04561 and Accession number 1002249.

\section{References}

Berenjian, A., Chan, N.L-C., Mahanama, R., Talbot, A., Regtop, H., ... \& Dehghani, F. (2013): Effect of biofilm formation by Bacillus subtilis natto on menaquinone-7 biosynthesis. Mol. Biotechnol., 54, 371-378.

Berenjian, A., Mahanama, R., Kavanagh, J. \& Dehghani, F. (2015): Vitamin K series: Current status and future prospects. Crit. Rev. Biotechnol., 35, 199-208.

Berenjian, A., Mahanama, R., Talbot, A., Biffin, R., Regtop, H., .. \& \& Dehghani, F. (2011a): The effect of aminoacids and glycerol addition on MK-7 production. Proc. World. Congr. Eng. Comput. Sci., Vol II. WCECS 2011, October 19-21, 2011, San Francisco, CA, USA

Berenjian, A., Mahanama, R., Talbot, A., Biffin, R., Regtop, H., ... \& Dehghani, F. (2011b): Efficient media for high menaquinone-7 production: response surface methodology approach. New Biotechnol., 28, 665-672.

Berenjian, A., Mahanama, R., Talbot, A., Regtop, H., Kavanagh, J. \& Dehghani, F. (2014): Designing of an intensification process for biosynthesis and recovery of menaquinone-7. Appl. Biochem. Biotech., 172, 13471357.

IkedA, H. \& DoI, Y. (1990): A vitamin-K2-binding factor secreted from Bacillus subtilis. Eur. J. Biochem., 192, 219-224.

Mahdinia, E., Demirci, A. \& Berenjian, A. (2017a): Production and application of menaquinone-7 (vitamin K2): a new perspective. World J. Microb. Biot., 33, 2.

Mahdinia, E., Demirci, A. \& Berenjian, A. (2017b): Strain and plastic composite support (PCS) selection for vitamin $\mathrm{K}$ (menaquinone-7) production in biofilm reactors. Bioproc. Biosyst. Eng., 40, 1507-1517.

Mahdinia, E., Demirci, A. \& Berenjian, A. (2018a): Optimization of Bacillus subtilis natto growth parameters in glycerol-based medium for vitamin K (menaquinone-7) production in biofilm reactors. Bioproc. Biosyst. Eng., 41, 195-204.

Mahdinia, E., Demirci, A. \& Berenjian, A. (2018b): Utilization of glucose-based medium and optimization of Bacillus subtilis natto growth parameters for vitamin $\mathrm{K}$ (menaquinone-7) production in bio film reactors. Biocatal. Agr. Biotechnol., 13, 219-224.

Mahdinia, E., Demirci, A. \& Berenjian, A. (2018c): Enhanced vitamin K (menaquinone-7) production by Bacillus subtilis natto in biofilm reactors by optimization of glucose-based medium. Curr. Pharm. Biotechno., 19(11), 917-924.

Mahdinia, E., Demirci, A. \& Berenjian, A. (2018d): Implementation of fed-batch strategies for vitamin K (menaquinone-7) production by Bacillus subtilis natto in biofilm reactors. Appl. Microbiol. Biot., 102(91), 9147-9157.

Mahdinia, E., Demirci, A. \& Berenjian, A. (2019a): Biofilm reactors as a promising method for vitamin K (menaquinone-7) production. Appl. Microbiol. Biot., 103(14), 5583-5592.

Mahdinia, E., Cekmecelioglu, D. \& Demirci, A. (2019b): Bioreactor scale-up. -in: Berenjian, A. (Ed.) Essentials in fermentation technology. Learning materials in biosciences. Springer, Cham, pp. 213-236.

Mahdinia, E., Demirci, A. \& Berenjian, A. (2019c): Effects of medium components in glycerol-based medium on vitamin K (menaquinone-7) production by Bacillus subtilis natto in biofilm reactors. Bioproc. Biosyst. Eng., $42,223-232$.

Mahdinia, E., Demirci, A. \& Berenjian, A. (2019d): Modeling of vitamin K (menaquinone-7) fermentation by Bacillus subtilis natto in biofilm reactors. Biocatal. Agr. Biotechnol., 17, 196-202. 
Okano, T., Shimomura, Y., Yamane, M., Suhara, Y., Kamao, M., .. \& Nakagawa, K. (2008): Conversion of phylloquinone (vitamin K1) into menaquinone-4 ( vitamin K2 ) in mice: tow possible routes for menaquinone-4 accumulation in cerebra of mice. J. Biol. Chem., 283, 11270-11279.

Sato, T., Yamada, Y., Ohtani, Y., Mitsui, N., Murasawa, H. \& Araki, S. (2001): Production of menaquinone (vitamin K2)-7 by Bacillus subtilis. J. Biosci. Bioeng., 91(1), 16-20.

Schurgers, L.J., Teunissen, K.J.F., Hamulyák, K., Knapen, M.H., ViK, H. \& Vermeer, C. (2007): Vitamin K-containing dietary supplements: comparison of synthetic vitamin K1 and natto-derived menaquinone-7. Blood, 109, 3279-3283.

Shearer, M.J. \& Newman, P. (2008): Metabolism and cell biology of vitamin K. Thromb. Haemostasis, 100, 530547.

Singh, R., Puri, A. \& PAnda, B.P. (2015): Development of menaquinone-7 enriched nutraceutical: Inside into medium engineering and process modeling. J. Food Sci. Tech., 52, 5212-5219. 